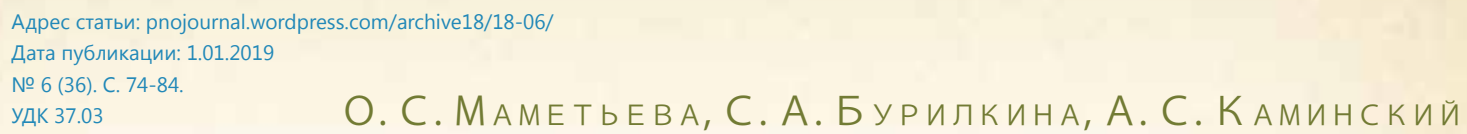

В статье представлен анализ эмпирического исследования, направленного на выявление готовности специалистов по социальной работе к реализации технологического подхода в работе с семьями, оценку специалистами личного опыта использования социальных технологий. Целью эмпирического исследования было выявить понимание студентами будущими специалистами по социальной работе, специфики реализации технологий социальной работы с семьей и готовность к их применению в решении социальных проблем семей разного типа. В ходе эмпирического исследования авторы анализируют проблемы в деятельности специалистов по социальной работе и оценку личного опыта использования социальных технологий.

В статье теоретически обоснована необходимость и возможность совершенствования готовности специалистов социальной сферы к реализации технологий социальной работы с семьями различных типов. Авторами разработаны методические рекомендации, которые включают такие вопросы как: повышение квалификации специалистов, усиление мотивации специалистов на получение эффективного результата; повышение профессионального уровня самоуправления $и$ организационной культуры; разработку стандартов социальной помощи, четких описаний соответствия задач, условий и результатов социальной работы установленной норме.

Ключевые слова: технологии социальной работы, готовность будущих специалистов, формирование готовности, семьи разных типов

Perspectives of Science \& Education. 2018. 6 (36)

International Scientific Electronic Journal

ISSN 2307-2334 (Online)

Available: psejournal.wordpress.com/archive18/18-06/

Accepted: 12 November 2018

Published: 1 January 2019

No. 6 (36). pp. 74-84.

O. S. Mameteva, S. A. Burilkina, A. S. Kaminskil

\title{
Formation in Social Sphere Specialists their Preparedness to Implement Social Technologies in Work with Families of Various Types
}

The article represents empirical research analysis, targeted to disclose the social specialists' preparedness to implement the technological approach in their work with families of various types, the specialists' personal experience in the use of social technologies evaluation. The scope of empirical research was to identify the understanding by the students - future specialists in social work, the specificity of implementing the technologies of social work with family and their preparedness to apply them in social problems solution with families of various types. In course of empirical research, the authors analyze the problems of social specialists' activities and evaluate their personal experience in the use of social technologies.

The article theoretically substantiates the requirement and possibility to improve the preparedness of social sphere specialists to implement the technologies of social work with families of various types. The authors have developed the methodological recommendations, incorporating the following challenges: specialists' qualification improvement, specialists' motivation enhancement in efficient result obtainment; professional level of self-government improvement and organizational culture increase; development of social support standards, distinct descriptions of tasks conformance, conditions and results in social work compliance with the established norm.

Key words: social work technologies, future specialists' preparedness, preparedness formation, families of various types 
учреждениями, организациями и специалистами, работающими с семьей. Однако на практике пока нет системного подхода и не выработан управленческий аппарат межведомственного взаимодействия.

4. Между необходимостью формализации, алгоритмизации действий специалистов учреждений социальной защиты, связанных с увеличением массовости охвата нуждающихся в социальной помощи и отсутствием инициатив, вдумчивой и последовательной работы специалистов и, соответственно, ориентацией на формальные критерии результативности. Сегодня специалисты вынуждены работать в условиях повышенной нагрузки, когда на одного специалиста приходится большой контингент клиентов (примерно 40-50 семей), и его задача при этом не «опоточивать» процесс помощи, а находить к каждой семье индивидуальный подход.

Материалы и методы ство в целом, так и отдельные слои общества. Для успешного решения данного вопроса необходимы совместные усилия специалистов в различных областях деятельности, в том числе, специалистов по социальной работе, владеющих различными технологиями решения социальных проблем.

Основная проблема данного исследования обусловлена сложившимися противоречиями в теории и практике социальной работы:

1. Между растущей технологизацией социальной сферы и недостаточным уровнем специалистов в реализации технологий социальной работы. Сегодня технологии все больше проникают во многие сферы жизнедеятельности. Специалист по социальной работе должен не только иметь представление о том, что такое социальные технологии и как они функционируют в сфере социальной работы, но и должен уметь их выбирать, применять, прогнозировать результат, быть компетентным в этом вопросе.

2. Между введением профессиональных стандартов, в которых прописаны компетенции, предполагающие не столько знания, сколько умения и владения специалистов и принятыми подходами к системе подготовки, переподготовки, повышения квалификации кадров специалистов учреждений социального обслуживания. Они ориентированы в большей степени на традиционные подходы и модели в обучении, чем на использование активных методов и технологий обучения, включение слушателей курсов в активную имитационную профессионально-образовательную деятельность, подготовку к решению проблемных профессиональных ситуаций и пр.

3. Между потребностями практики социальной работы и отсутствием благоприятных условий и механизмов ее реализации. Для эффективной реализации технологий социальной работы требуется тесное конструктивное межведомственное взаимодействие между всеми

В своем исследовании мы исходили из предположения, что реализация социальных технологий в современной практике работы с семьей будет более успешной, если:

а) имеется организационно отработанная координация между учреждениями, организациями, органами и специалистами различной ведомственной подчиненности;

б) специалист, работающий с семьей, компетентен в вопросах выбора и применения определенных технологий в зависимости от типа и проблем конкретной семьи;

в) специалист постоянно совершенствует свою деятельность и помимо традиционных, использует инновационные формы и методы работы;

г) у специалиста есть понимание трудностей, возникающих на определенном этапе работы и умение прогнозировать ее результаты.

Для подтверждения данной гипотезы нами был проведен опрос методом анкетирования специалистов по социальной работе и студентов-выпускников, обучающихся по направлению подготовки «Социальная работа».

Объект исследования - готовность специалистов социальной сферы к реализации технологий социальной работы с семьями различных типов.

Цель работы - теоретическое обоснование процесса формирования готовности специалистов социальной сферы к реализации технологий социальной работы с семьей в процессе обучения и профессиональной деятельности.

Методологической базой исследования является: деятельностный, личностно-ориентированный, системный и индивидуально-творческий подходы (Ш.А. Амонашвили, Л.С. Выготский, П.Я. Гальперин, В.В. Давыдов, В.Е. Зинченко, А.Н. Леонтьев, А.К. Маркова, Н.В. Кузьмина, А.В. Петровский, С.Л. Рубинштейн, В.В. Сериков, В.Н. Сластенин, Д.Б. Эльконин и др.); теории и концепции 
готовности специалиста к определённому виду профессиональной деятельности (В.П. Бездухов, М.И. Дьяченко, Л.А. Кандыбович, В.Ш. Масленникова);

Методы исследования: теоретические: анализ научной литературы по проблеме исследования; эмпирические: анкетирование будущих специалистов по социальной работе и анализ применения технологий специалистами-практиками в работе с семьями различных типов; статистические: количественная обработка, качественный анализ результатов исследования.

Наряду с этим опрос предполагал выявление проблем и возможных путей их решения в деятельности специалистов по социальной работе и оценку личного опыта использования социальных технологий. Относительно выпускников целью исследования было выявить понимание специфики реализации технологий социальной работы с семьей и готовность к их применению. Практически все вопросы анкеты были полузакрытыми, то есть предусматривали возможность для специалистов не только выбрать подходящий вариант ответа из предложенных, но и высказать свое мнение, сформулировав другой вариант ответа.

Результаты исследования

В опросе приняло участие 116 специалистов: МУ «Центр социальной помощи семье и детям» г. Магнитогорска, МУ «Комплексный центр социального обслуживания населения» Орджоникидзевского района г. Магнитогорска, 58 студентов Института гуманитарного образования. В результате количественной и качественной интерпретации анкетных данных мы получили следующие результаты.

Сначала остановимся на таком показателе как профессионализм специалистов, который складывается из возраста, опыта работы и образовательного уровня. Следует отметить, что эти вопросы отсутствовали в анкете, которую заполняли студенты, поскольку данные показатели в отношении студентов для нас не имели значение.

Значительное большинство респондентов (79,3 \%) работают в социальных службах менее 5 лет. Также 10,3 \% социальных работников работают свыше 5 лет. И всего лишь 3,4 \% и 6,9 \% опрошенных работают в данных учреждениях более 10 и 15 лет соответственно. Что касается возраста специалистов, стоит отметить «омоложение» работников - почти половине респондентов $(48,3$ \%) менее 30 лет. Треть от общего числа работников (34,5\%) находится в возрастной границе от 29 до 39 лет. Самые «возрастные» - это, в основном, специалисты старше 50 лет, составляют лишь 6,9 \% от общего числа работников.

Данные нашего исследования позволяют говорить о приходе в отрасль социальной защиты населения молодых людей, что несколько проти- воречит стереотипу восприятия специалиста по социальной работе или социального работника как «женщины в возрасте далеко за сорок» в теории и практике социальной работы.

Далее мы предположили, что возможно, недостаток опыта компенсируется уровнем профессиональной подготовки. Ответы получились двоякими: несмотря на то, что 73,2 \% респондентов имеют высшее образование, тем не менее, всего 47,4 \% отметили наличие высшего образования именно по профилю работы. Остальные получают образование по программам дополнительного профессионального образования. Отсюда видно, что в целом коллективы достаточно образованы, обладают определенным уровнем знаний, умений, но в деятельности социальных служб процесс профессионального становления кадров еще не завершен и требует более пристального внимания со стороны руководства.

По данным нашего исследования наибольшее число респондентов-специалистов отметили, что наиболее часто становятся клиентами социальной службы: неполные $(62,1 \%)$, неблагополучные $(55,2 \%)$ и многодетные (48,3 \%) семьи, что является вполне закономерным, поскольку именно эти типы семей в первую очередь относятся к категории риска и, соответственно, больше нуждаются в помощи и поддержке со стороны государства. Примерно одинаковое количество ответов набрали варианты замещающие семьи (37,9 \%), семьи с инвалидом (34,5\%) и безработные семьи (34,5\%).

Интересно, что студенты выбрали несколько другие варианты ответа на этот вопрос. В частности, на первое место они определили многодетную семью как наиболее частого клиента учреждений социальной защиты (62,1%). Это подтверждает выбранную нами стратегию описания проблем семьи, когда стереотип восприятия в обществе благополучия или неблагополучия семьи напрямую зависит от позиции ее количества детей. Следует отметить, что и на занятиях в процессе обучения на вопрос о том, какая семья является наиболее нуждающейся или неблагополучной, очень часто студенты называют многодетную семью. Второе место выпускники отдали семье с инвалидом. Данный выбор можно объяснить тем, что, по мнению студентов, эти семьи чаще становятся клиентами социально-реабилитационных центров, которые относятся к учреждениям социальной защиты.

Ранжирование основных проблем этих семей показало, что на первое место подавляющее большинство специалистов (86,2 \%) поставили социально-экономические проблемы. Второе место заняли социально-психологические проблемы (58,6 \%); третье и четвертое - затруднения педагогического и бытового характера $(41,4$ \% и 37,9 \%). Это свидетельствует о том, что проблемы, с которыми сталкиваются современные семьи, касаются разных сторон жизни: социаль- 
ной, правовой, материальной, медицинской, психологической, педагогической и других.

При этом только одна проблема у семьи встречается довольно редко, поскольку все они взаимосвязаны и взаимообусловлены. Например, социальная неустроенность приводит к психологическому напряжению, что порождает семейные конфликты; материальная ограниченность не позволяет удовлетворять насущные потребности, отрицательно сказывается на физическом и психическом здоровье взрослых и детей.

Ответы специалистов и студентов, отличаются по всем показателям, кроме одного. Студенты также, как и специалисты, чаще всего отмечали вариант «Социально-экономические проблемы» (77,6 \%), поскольку значимость указанной проблемы ни у кого не вызывает сомнений. С вы- сокой степенью вероятности предположим, что причины различий в ранжировании проблем семей могут лежать в соотношении теории и практики. Поскольку студенты отвечают на вопросы, исходя из теоретических знаний социальной работы и той информации, которую получают в процессе обучения, а специалисты - исходя из своей практической деятельности.

Технологию социальное консультирование в работе с семьей использует подавляющее большинство специалистов (72,4 \%). Многообразие проблем и сложностей, с которыми сталкиваются семьи различных типов, приводит к существованию таких видов консультирования как медико-социальное, социально-педагогическое, социально-психологическое, социально-правовое, управленческое и другие (см. табл. 1).

Таблица 1

Технологии, используемые в социальной работе с семьями

\begin{tabular}{|l|c|c|}
\hline \multicolumn{1}{|c|}{ Варианты ответа } & $\begin{array}{c}\text { \% от числа ответивших } \\
\text { специалистов }\end{array}$ & $\begin{array}{c}\text { \% от числа ответивших } \\
\text { студентов }\end{array}$ \\
\hline социальная профилактика & 27,6 & 19,0 \\
\hline социальное обслуживание & 20,7 & 58,6 \\
\hline социальное консультирование & 72,4 & 60,3 \\
\hline социальная терапия & 3,4 & 10,3 \\
\hline социальное посредничество & 13,8 & 6,9 \\
\hline социальная реабилитация & 34,5 & 27,6 \\
\hline социальное сопровождение & 20,7 & 39,7 \\
\hline социальный патронаж & 51,7 & 36,2 \\
\hline социальная диагностика & 31,0 & 6,9 \\
\hline реализация проектных программ & 13,8 & 31,0 \\
\hline
\end{tabular}

На втором месте специалисты указали социальный патронаж (51,7 \%). Метод социального патронажа - это вид социального обслуживания клиентов и групп риска, в большей степени на дому, заключается в постоянном социальном надзоре, постоянном посещении их лиц специалистами по социальной работе, оказании гражданам нужной поддержки. Во время патронажа специалист посещает квартиру, исследует жилищно-бытовые условия, знакомится с семьей, родственниками, следит за семьей в обыкновенной домашней обстановке, изучает ее психологический климат, обстановку, в какой живут дети. Почувствовать психоэмоциональную атмосферу, царящую в семье, можно исключительно в обычной для нее обстановке. У специалиста, благодаря социальному патронажу, появляется возможность проведения доверительных бесед, освобождающих родителей от испуга и неуверенности перед лицом официальных инстанций.

Социальную реабилитацию, равно как социальную профилактику и диагностику отметили почти треть респондентов. Вероятнее всего, это свидетельствует не только о востребованности данных технологий, но и о компетентности специалистов в их реализации. В соответствии с этим, значение, которое придают специалисты социальной профилактике, является хорошей тенденцией и позволяет предположить получение благоприятных результатов их деятельности.

Меньше всего специалисты используют такие технологии в своей работе, как «социальное посредничество» (13,8 \%) и «реализация проектных программ» (13,8 \%). Мы полагаем, что нечастое использование указанных технологий говорит не столько об их невостребованности, сколько о трудностях, с которыми специалисты сталкиваются при их применении, и которые носят как объективный (при посредничестве), так и субъективный характер (в реализации проектных программ).

В отличие от специалистов-практиков, студенты отвечали с позиции «как это должно быть». Они также отметили социальное консультиро- 
вание (60,3 \%) и не забыли про социальный патронаж (36,2 \%). Большое значение студенты (в отличие от специалистов - 20,7 \%) придали социальному сопровождению как технологии социальной работы (39,7 \%), т.к. это одна из новых и актуальных форм работы с семьей. Сопровождение семьи относится к пролонгированной помощи, важнейшими характеристиками которой является комплексность (получение различных услуг: социальных, психологических, педагогических и т.д.) и участие профессиональной команды специалистов, придерживающихся в своей деятельности единой концепции. На практике нечасто используется специалистами, потому что ее методологическая основа и нормативная база требует доработки на разных уровнях.

Однако реализации проектных программ студенты придают немаловажное значение (31,0 \%), поскольку моделирование и проектирование позволяют, прежде всего, осуществлять управляемость и регулируемость не столько процессом оказания помощи, сколько собственной деятельностью специалиста по социальной работе. Казалось бы, осознание этого будущими специалистами позволяет надеяться на практическое воплощение их знаний на практике.

Проектная деятельность предусматривает внедрение инноваций, а поскольку специалисты не отдают предпочтение данному виду деятельности, то внедрение инноваций, а также сочетание традиционных и инновационных форм на практике является затруднительным. Несмотря на то, что будущие специалисты отмечают значимость этого, то на практике они «уходят» от этого вида деятельности, поскольку он очень трудоемкий и сложный.

Нас интересовало, на каком из этапов применения технологий могут возникать трудности. Почти половина респондентов (48,1 \%) отметили, что это третий этап, на котором осуществляются действия в соответствии с планом, включая взаимодействие со всеми заинтересованными организациями; контрольные посещения семьи, встречи с ребенком. Специалисты испытывают сложности в выстраивании работы с клиентами. Причины могут заключаться в следующем: им зачастую сложно попасть в неблагополучную семью из-за аморального поведения родителей, при работе с клиентами сталкиваются с такой проблемой, как агрессивность самих родителей. Также следует отметить трудности при работе с детьми, указывая на то, что они не желают идти на контакт со специалистами. Возникают трудности при общении с клиентами: низкий интеллектуальный уровень, психические заболевания родителей, нежелание родителей менять свою жизнь к лучшему.

Однако большинство трудностей испытывают чуть больше половины респондентов (51,9 \%) на начальном этапе реализации технологий. На этом этапе осуществляются операции вы- явления, оценки и ранжирования проблем, выяснения факторов, обусловивших ее возникновение. Организатор социальной деятельности настраивается на ее решение, мобилизует свой интеллектуальный, морально-психологический и профессиональный потенциал. Одновременно уточняются критерии действительности и эффективности деятельности социальных служб при решении обозначенной социальной проблемы. При этом критерии успеха действий социальных служб и специалистов могут отражаться в постановке и формулировании цели и конкретных задач социальной работы. Сложности возникают и на третьем этапе, когда происходит воздействие на семью, взаимодействие с организациями, контрольные посещения в семью.

Мы проанализировали основные причины затруднений, испытываемых специалистами при реализации технологий социальной работы с семьей. Главной причиной, препятствующей эффективной работе более половины опрошенных (64,3 \%) считают отсутствие организационно-отработанной координации между ведомствами. Деятельность социальной службы и отдельного специалиста зависит от продуктивного взаимодействия с различными организациями и ведомствами, однако следует учитывать, что эффективность такого взаимодействия может быть низкой из-за слабой заинтересованности этих ведомств в поддержке деятельности специалиста по социальной работе.

Объективная трудность заключается в том, что довольно трудно добиться слаженных действий специалистов разных ведомств по конкретным трудным жизненным ситуациям, в которых оказывается семья и дети. Медленное развитие межведомственного взаимодействия, отсутствие согласованности действий специалистов разных ведомств на сегодняшний день является одним из серьезных ограничений в реализации технологий социальной работы, требующих комплексного подхода (социальный патронаж, диагностика, реабилитация). Значительную сложность при оказании услуг составляет сбор документов, проблематичным оказывается взаимодействие с другими инстанциями, которые, как отмечают специалисты, не всегда входят в положение.

Респонденты отметили, что имеются проблемы большой нагрузки в рамках выполняемой работы - 28,6 \%, недостаточный объём финансирования - 25,0 \% и несовершенство законодательной базы - 21,4%. При таком ранжировании трудностей, когда значительная часть опрошенных сводит их, прежде всего, к «внешним», не зависящим от самих специалистов непосредственно, трудно рассчитывать на эффективную мотивацию решения проблем данного уровня.

Важным ресурсом повышения качества работы персонала является создание определенных условий, способствующих повышению мотивации и профессионального уровня сотрудников. 
Речь идет об организации системы повышения квалификации сотрудников, удовлетворенности трудом, благоприятном климате в коллективе, позитивной корпоративной культуре, выработке и соблюдении высоких стандартов работы. Необходима также адекватная нагрузка на специалиста, оставляющая время для вдумчивой работы с отдельными клиентами, снижающая риск профессионального выгорания и повышающая возможности для профессионального совершенствования, применения инновационных технологий работы. Сюда же относится уровень оснащенности техническими средствами, правильная эргономика рабочего места, благоприятные условия труда на рабочем месте, наличие транспорта, обеспечение проездными билетами, обеспечение мебелью, оборудованием, литературой, связью и, не в последнюю очередь, адекватная оплата труда и мотивации через различные механизмы оплаты труда.

Специалисты отмечают, что ограничены финансовые ресурсы, имеющиеся в распоряжении исполнительных органов власти на федеральном, региональном и местном уровнях, а также недостаточно используются финансовые средства, материально-технические и интеллектуальные возможности негосударственных учреждений. Слабость материально-технической базы учреждений сказывается на качестве социальной работы. Пока еще чрезвычайно мало специально спроектированных комплексов, зданий, помещений. В основном центры расположены в приспособленных помещениях. Не хватает реабилитационного оборудования, средств связи, автотранспорта, компьютерно-вычислительной техники, медикаментов, продуктов питания и т.д. По-прежнему остается недостаточно разработанной правовая база системы социального обслуживания.

Анализируя ответы студентов-выпускников, обратим внимание, прежде всего, на те, которые отличались от выбранных специалистами.

Так, большая нагрузка в рамках выполняемой работы была предположением в качестве возможных затруднений при реализации технологий лишь у 12,5 \% респондентов. В то время как специалисты, испытывающие на практике это затруднение, составили 28, 6 \% от общего числа опрошенных.

Еще одно «разногласие» вызвал ответ «недостаточный объем финансирования». Осмелимся предположить, что расхождение в ответах (специалисты-практики - 25,0%, студенты - 44,6 \%), вызвано скорее завышенными требованиями современной молодежи относительно всего, что касается финансирования.

Специалисты отметили и «трудности в формулировании целей работы с семьей» - 17,9 \%, и «проблемы квалификации и компетентности специалистов» - 10,7 \%, и «недостаточное владение диагностическим инструментарием»
- 7,1\%. Возможно, в данном случае это обосновано недостаточно высоким уровнем профессиональной подготовки работников. Исследование свидетельствует, что только четверть из них имеет специальное высшее образование. Поэтому вполне логично, что почти половина респондентов $(46,4 \%)$ высказали мнение о необходимости повышения своей квалификации.

За внедрение инновационных технологий и обеспечение комплексной работы высказались 57,1 \% и 53,6 \% респондентов соответственно. Знания об инновационных технологиях социальной работы, грамотное использование их в практике в настоящее время становится обязательным условием личностной и профессиональной готовности специалиста по социальной работе к выполнению своего функционала, повышения эффективности его деятельности. В связи с этим отметим, 62,1 \% опрошенных признали, что только частично знакомы с современными инновационными технологиями в сфере социальной работы с семьей. Студенты же гораздо скромнее оценили свое знакомство с инновационными технологиями. Так, признались, что не знают никаких инновационных технологий в социальной работе с семьей 17,9 \% и затруднились ответить на этот вопрос 12,5\%.

В большинстве случаев знакомство с современными инновационными технологиями (и, соответственно, их дальнейшая разработка и реализация) происходит в практической деятельности. Теоретическое же обучение студентов построено в большей степени на традиционных подходах, что заставляет задуматься о необходимости изменений в содержании и формах образовательного процесса в соответствии с сегодняшними реалиями [12].

Обсуждение результатов

По результатам нашего исследования большинство специалистов используют различные технологии социальной работы с семьей, их выбор и реализация зависят от множества факторов, как объективных, так и субъективных. В связи с этим, имеются определенные трудности при реализации социальных технологий:

- не разработаны механизмы и четкие критерии взаимодействия различных ведомств и организаций на муниципальном уровне;

- имеются трудности во внедрении инновационных технологий в социальной работе, поскольку специалисту сложно перейти от формального и стандартного к творческому и инновационному подходу;

- у специалистов, работающих с семьей, имеются трудности в оценки состояния семьи и ребенка, соответственно, это проявляется в выборе и применении определенных технологий в зависимости от типа и проблем конкретной семьи; 
- не всегда у специалиста есть осознание проблем, возникающих на определенном этапе работы, и умение прогнозировать результаты (поскольку изначально грамотному формулированию цели не придается важное значение).

На основании Федерального государственного образовательного стандарта высшего профессионального образования третьего поколения по направлению «Социальная работа» выпускник должен обладать следующими компетенциями:

- общекультурными компетенциями, куда относят культуру мышления, способность к обобщению, анализу, восприятию информации, логике и аргументации собственной речи, умение сотрудничать, находить решения в нестандартных ситуациях и быть готовым нести за них ответственность, знание и умение работать с нормативно-правовыми документами, стремлением к саморазвитию повышению квалификации и мастерства, владение одним из иностранным языком и др.

- профессиональными компетенциями, которые включают в себя способность самостоятельно с помощью информационных технологий, и использовать в практической деятельности новые знания и умения, способность на научной основе организовывать свой труд, самостоятельно оценивать результаты своей деятельности, владеть основными методами, способами и средствами получения, хранения и переработки информации [15].

Вышеупомянутый стандарт немаловажен в практической деятельности специалиста по социальной работе. Однозначно, определение профессиональной компетентности зависит от той области, в которой задействован специалист.

Для обучающегося важно понимание и осознание того, что стать успешным человеком в условиях рынка сможет тот, кто имеет хорошую профессиональную подготовку, способен к саморазвитию, умеет самостоятельно работать, решать проблемы, проявлять инициативу, обладает способностью адаптироваться к новым условиям труда, быть мобильным специалистом. В этой связи встает проблема совершенствования теоретической и практической подготовки специалистов, способных продуктивно решать задачи, связанные с реализацией технологий социальной работы с семьями различных типов.

Для решения выявленных проблем использования технологий социальной работы с различными семьями в результате анкетирования студентов по специальности «Социальная работа» и специалистов социальных служб, нами были разработаны следующие рекомендации.

1. Компетентность специалистов. В социальных учреждениях должны работать квалифицированные специалисты, имеющие базовое образование, знающие современную семью, ее проблемы, тенденции развития, компетентные в вопросах оказания ей социальной, правовой, психолого-педагогической и иной помощи [6]. Сегодня унификация социальных услуг и введение профессионального стандарта выходит на повестку дня в учреждениях отрасли «социальная защита». Актуализация этого процесса позволяет выделить определенные трудности:

Во-первых, противоречие формализации. В социально-реабилитационной, коррекционной, адаптационной работе с семьей и детьми имеется противоречие между необходимостью формализации, алгоритмизации действий специалистов учреждений социальной защиты, связанных с увеличением массовости охвата нуждающихся в социальной помощи и отсутствием инициатив, вдумчивой и последовательной работы специалистов и, соответственно, ориентацией на формальные критерии результативности. В качестве закономерного ответа органов и учреждений на требования государства в области социальной защиты, количество различных операций и процедур постоянно увеличивается, степень их формализации растет. И такой путь технологизации социальной помощи, «раскладывания по полочкам» заданий и мероприятий специалистов в настоящее время остается единственно правильным.

С другой стороны, формализация порядка действий специалистов нередко становится основанием для торможения инициатив, работы исключительно "для галочки». В любой технологии социальной работы с семьей и детьми, таким образом, скрыт механизм эффективного увеличения массовости охвата нуждающихся социальной помощью. При этом нормативноалгоритмическая природа этого механизма при изначальной ориентации на формальные критерии результативности, создает в определенных общественных условиях серьезные ограничения эффективной деятельности специалистов. Реагируя на разнообразные факты неорганизованности и несогласованности работы органов и учреждений социальной защиты, государство и общество требуют уделить особое внимание отчетности, планированию, контролю.

Данная тенденция сохраняется, несмотря на описанное выше противоречие, и, по-видимому, эта тенденция развития социальной работы будет актуальна в ближайшие десятилетия. В сфере добровольчества, в так называемом третьем секторе, система процедур является менее строгой, однако необходимость в ней также сохраняется, т. к. многие волонтерские организации, заключая договоры с органами власти или грантодателями, должны продемонстрировать наличие технологического подхода к решению проблем семьи и детей.

Для преодоления данных трудностей возможно применение следующих мер:

- повышение квалификации специалистов;

- усиление мотивации специалистов на получение эффективного результата;

- повышение профессионального уровня са- 
моуправления и организационной культуры;

- распространение положительного опыта ра-

боты среди сотрудников социальных служб;

- дальнейшая разработка стандартов соци-

альной помощи, то есть четких описаний соответствия задач, условий и результатов социальной работы установленной норме;

Во-вторых, существуют проблемы и в определении границ ситуации и роли личности специалиста. Каждая технология социальной работы имеет свои границы применения. Они определяются самыми разными объективными и субъективными обстоятельствами. Задача социального работника, психолога, педагога - правильно провести границы применимости данной технологии к данной трудной жизненной ситуации [9]. В 21 веке на первый план социальной работы выходит уже не то, что и как делается, а то, кем это делается. Технологии открыты для освоения, но одних знаний далеко недостаточно. Нужны высококлассные умения и навыки, синтезированные с положительными личными качествами [7].

Особенно это требование предъявляется выпускникам, окончившим программу подготовки 39.03.02 «Социальная работа», которые в рамках профессиональной деятельности должны быть готовы решать такие задачи, как:

- самостоятельное (на уровне технологического процесса) и творческое осуществление, поиск оптимального способа оказания социальной помощи и услуг отдельным лицам, социальным группам (семьям различного типа);

- разработка и эффективное применение социальных технологий, учитывающих особенности современного сочетания глобального, национального и регионального, специфику социокультурного развития человека и общества, обеспечения его социального здоровья.

Квалифицированный профессионал, являющийся разносторонней полноценной личностью - главный и единственный субъект, способный правильно проводить границы рассмотрения трудных жизненных ситуаций, в которые попадают дети и семьи.

Специалист социальной службы, будь то организатор или исполнитель, выстраивает определенные модели своей профессиональной деятельности, добиваясь максимальной рационализации собственных усилий. Понимание задач социальной работы прямо или косвенно воплощается в определенных процедурах действий специалиста и их последовательности. При этом эффективность этих алгоритмов определяется, прежде всего, ситуацией, которая складывается как совокупность сформировавшихся объективных условий и субъективных движущих сил. Рамки применимости технологии к ситуации определяют технологический потенциал моделей социальной работы, то есть возможную скорость и целесообразность алгоритмизации теоретических положений. Только профессионально под- готовленный специалист по социальной работе способен адекватно сформировать модель своих действий, обнаружить границы сложившейся ситуации и аккуратно “вложить» социальную технологию в данные границы [1].

Таким образом, для более эффективной реализации технологий социальной работы с семьей и детьми необходимо:

- изменить подходы к системе подготовки, переподготовки, повышения квалификации кадров специалистов учреждений социального обслуживания, несмотря на сложности в «перестройке» мышления педагогов, ориентированных в большей степени на традиционные подходы и модели в обучении.

- усилить координацию деятельности исследовательских коллективов и практиков в разработке современных, социальных технологий, новейших форм и методов социальной работы с различными категориями семьи и детей;

- организовать эффективное сотрудничество различных органов, учреждений, организаций и специалистов, т. е. обеспечить межведомственный подход к ведению случая;

- находить дополнительные возможности для повышения квалификации работников социальных служб;

- преодолевать объективные и субъективные трудности в становлении специалиста в области социальной работы;

- вырабатывать необходимые профессиональные компетенции у специалистов в сфере социальной защиты населения по запросу самих специалистов или учреждений.

Развитие государства диктует необходимость сохранения значимости семьи как важного социального института и делает актуальным совершенствование института профессиональной подготовленности специалистов по социальной работе с семьей, формирования у них готовности к решению семейных проблем различного уровня сложности [2]. Деятельность таких специалистов с позиции имеющегося на сегодняшний день научно-практического представления являет собой сложный по функциональному и ролевому разнообразию вид социальной деятельности, постоянно осуществляемый в режиме интегративно связанных действий и многофункциональности, требующих интенсификации всех имеющихся у социального работника ресурсов.

Изложенное свидетельствует о важности подготовки специалистов социальной сферы, способных к реализации различных технологий социальной работы с семьей [3]. Приоритетность технологического подхода в сфере защиты семьи и детства обусловлена его спецификой: алгоритмами обслуживания, планированием процедур оказания социальных услуг, контролем их качества и отчетностью.

Технологии в России активно развиваются на протяжении нескольких десятилетий. Сформи- 
ровалась нормативно-правовая база, позволяющая обеспечить технологический подход, а в учреждениях социальной защиты накопился серьезный опыт применения конкретных услуг и методов социальной поддержки семьи и защиты несовершеннолетних.

Однако сами по себе социальные услуги представляют собой лишь конкретные операции или процедуры оказания социальной помощи, входящие в те или иные технологии как составляющие элементы. Технологию социальной работы отличает от социальной услуги большая степень сложности, комплексность, алгоритмичность. От метода социальной работы технологию отличает ориентация на конкретное решение типичной проблемы, единство процедур, алгоритмов и инструментария [14].

В связи с тем, что проблемы и потребности у семей разные, спектр услуг и применяемых методов сегодня недостаточен для их решения и удовлетворения, особенно на ранних стадиях семейного кризиса, появилась необходимость в разработке базового (минимального) пакета профилактических услуг, их стандартизации, а также в освоении и реализации региональных и муниципальных программ в сфере профилактики и ликвидации детского (семейного) неблагополучия, введение системы контроля качества предоставляемых услуг, соответствующей системы подготовки, переподготовки и методического сопровождения специалистов, супервизии их деятельности, способствующей овладению и успешному применению современных технологий и методик [10].

Заключение

В результате исследования мы выяснили, что в социальной работе с семьёй отдельные технологии работы не удовлетворяют всей совокупности проблем и трудностей семьи, поэтому требуют комплексного применения с учетом потребностей семьи. Также ошибочным будет выделение каких-либо определенных технологий по отношению к конкретным типам семей. Специфика применения технологий социальной работы к семьям различного типа заключается с одной стороны, в универсальности технологической стороны процесса (его алгоритмизация) и уникальности его содержания (применение различных методов и приемов в зависимости от проблемного поля семьи), с другой.
Здесь вся ответственность за качество и эффективность поддержки ложится на плечи команды специалистов. При этом специалисты должны уметь:

- во-первых, грамотно диагностировать состояние семьи;

- во-вторых, владеть разнообразными технологиями работы с семьей;

- в-третьих, своевременно и правильно их применять.

Только при выполнении этих требований можно ожидать положительных результатов работы с семьей и детьми.

В ходе эмпирического исследования нас интересовали проблемы в деятельности специалистов по социальной работе и оценка личного опыта использования социальных технологий, а целью опроса студентов было выявить понимание специфики реализации технологий социальной работы с семьей и готовность к их применению. Использование нескольких источников позволило нам получить более объективное и полное представление об исследуемой проблеме, на основе которого были сформулированы методические рекомендации.

Для совершенствования подготовки и деятельности специалистов в социальной сфере и повышения эффективности применения технологий социальной работы необходимы модернизация в системе работы с детско-семейным неблагополучием и перестройка деятельности с учетом следующих приоритетов:

- проблемно-ориентированный подход (понимание специалистами не только проблематики семей, но и осознание трудностей и путей их решения в процессе работы с семьей);

- проектно-инновационный подход (широкое применение технологий моделирования и проектирования, которые позволяют осуществлять качественное планирование и управление деятельностью, особенно при использовании новых методов и форм социальной работы с семьей);

- межведомственный (междисциплинарный) подход (согласованность работы и сотрудничество специалистов различных органов, учреждений, оказывающих услуги семье);

- практико-ориентированный подход (подготовка и переподготовка специалистов социальной работы должны быть направлены на формирование профессиональных компетенций, которые включают, прежде всего, умения и навыки).

1. Mameteva O.S., Rashchikulina E.N., Potrikeeva O.L., Bezenkova T.A., Burilkina S.A. Methods of developmental control in formation of students' socio-pedagogical thinking. Man in India. 2017. T. 97. № 5. C. 105-127.

2. Rashchikulina E.N., Plugina N.A., Panova L.P., Kondrashova E.N, Bezenkova T.A., Mameteva O.S. Development of dialectical thinking in students as a factor in improving the quality of higher education in technical universities. Journal of Applied Engineering Science. 2018. T. 16. C. $292-306$.

3. Бахчиева О.А., Савченко С.Л. Профессиональная подготовка социальных работников в условиях реализации новых технологий [Электронный ресурс] // Современные наукоемкие технологии. 2017. № 12. C. 73-78. URL: 
http://www.top-technologies.ru/ru/article/view?id=36874 (дата обращения: 09.10.2018).

4. Беспалько В. П. Педагогика и прогрессивные технологии обучения. М., 2015.

5. Голенкова О.В. Модель профессиональной подготовки будущих социальных работников к сопровождению детей, оставшихся без попечения родителей [Электронный ресурс] // Современные проблемы науки и образования. 2012. № 2. URL.: https://www.science-education.ru/ru/article/view?id=5970 (дата обращения: 4.10.2018)

6. Дружинина А.А. Формирование компетенций в области социальных инноваций у будущего социального работника. Социально-экономические явления и процессы. 2014.Т.9. № 10. С. 209-216.

7. Истомина К.В., Никитова С.Г. Социально-психологический подход к подготовке специалистов по социальной работе. Наука и Мир. 2015. Т. 2. № 9 (25). С. 174-175.

8. Машиньян А.А., Кочергина Н.В. О компетентности и компетенциях в образовании. [Электронный ресурс] // Перспективы науки и образования. 2015. 5 (17). URL.: http: // pnojournal.wordpress.com/archive15/15-05 (дата обращения: 1.10.2018)

9. Мишина Е.И.Условия и средства формирования личностной рефлексии будущихспециалистов. [Электронный ресурс] // Перспективы науки и образования. 2013. № 4. URL.: https://pnojournal.wordpress.com/2015/06/15/ mishina/ (дата обращения: 28.09.2018)

10. Олейник Е.В., Потрикеева О.Л. К вопросу о профессиональных и образовательных стандартах. Гуманитарнопедагогические исследования. 2017. Т. 1. № 2. С. 79-83.

11. Ращикулина Е.Н., Степанова Н.А. Содержательные аспекты профессиональной подготовки студентов к развитию познавательных способностей детей // Мир науки, культуры, образования. 2012. № 2 (33). С. 133-135

12. Романова Л.Л. Подготовка будущих бакалавров социальной работы к осуществлению профилактики семейного неблагополучия : автореф. дис. ... канд. пед. наук : 13.00.08. Тольятти. 2016. 25 с.

13. Самусева Г.В. Методические рекомендации по использованию критериально-диагностического инструментария для изучения готовности обучающихся к реализации опыта проявления позиции субъекта учебной деятельности. [Электронный ресурс] // Перспективы науки и образования. 2013. № 6. URL.: https:// pnojournal.wordpress.com/2015/06/17/samuseva-3/ (дата обращения: 17.11.2018)

14. Саралиева 3. Х. Инновационные социальные макро-, мезо- и микро-технологии // Вестник Нижегородского университета им. Н. И. Лобачевского. 2013. № 3. С. 152-158.

15. Федеральные государственные образовательные стандарты высшего профессионального образования (ФГОС) утвержденные и введены в действие. [Электронный ресурс]. URL.: http://www.tusur.ru/ru/education/ documents/federal/go. (дата обращения 17.11.2018)

REFERENCES

1. Mameteva O.S., Rashchikulina E.N., Potrikeeva O.L., Bezenkova T.A., Burilkina S.A. Methods of developmental control in students of socio-pedagogical thinking. Man in India. 2017. V. 97. no 5. pp. 105-127.

2. Rashchikulina E.N., Plugina N.A., Panova L.P., Kondrashova E.N., Bezenkova T.A., Mameteva O.S. Development of technical thinking in technical schools. Journal of Applied Engineering Science. 2018. V. 16. pp. 292-306.

3. Bakhchieva O.A., Savchenko S.L. Professional training of social workers in the implementation of new technologies [Electronic resource]. Modern high technologies. 2017. no. 12. pp. 73-78. Available at: http://www.top-technologies. $\mathrm{ru} / \mathrm{ru} / \mathrm{article} / \mathrm{view}$ ?id=36874 (accessed 9 October 2018). (in Russian)

4. Bespalko V.P. Pedagogy and progressive learning technologies. Moscow, 2015. (in Russian)

5. Golenkova OV Model of professional training of future social workers to accompany children left without parental care [Electronic resource]. Modern problems of science and education. 2012. no. 2. Available at: https://www. science-education.ru/ru/article/view?id=5970 (accessed 4 October 2018) (in Russian)

6. Druzhinina A.A. Formation of competences in the field of social innovation in the future social worker. Socioeconomic phenomena and processes. 2014. Vol. 9, no. 10. pp. 209-216. (in Russian)

7. Istomina K.V., Nikitova S.G. Socio-psychological approach to the training of specialists in social work. Science and Peace. 2015. V. 2. no. 9 (25). pp. 174-175. (in Russian)

8. Mashinyan A.A., Kochergina N.V. On competence and competences in education. Perspectives of science and education. 2015. no. 5 (17). Available at: http: // pnojournal.wordpress.com/archive15/15-05 (accessed 10 October 2018) (in Russian)

9. Mishina El. Conditions and means of forming personal reflection of future specialists. Perspectives of science and education. 2013. № 4. Available at: https://pnojournal.wordpress.com/2015/06/15/mishina/ (accessed 10 October 2018) (in Russian)

10. Oleinik E.V., Potrikeeva O.L. On the issue of professional and educational standards. Humanitarian and educational research. 2017. Vol. 1, no. 2. pp. 79-83. (in Russian)

11. Rashchikulina E.N., Stepanova N.A. Content aspects of students' professional training for the development of children's cognitive abilities. World of Science, Culture, Education. 2012. no. 2 (33). pp. 133-135 (in Russian)

12. Romanova L.L. Preparation of future bachelors of social work for the implementation of the prevention of family distress. Abstract Diss. PhD Ped. Sci.: 13.00.08. Tolyatti. 2016. 25 p. (in Russian)

13. Samuseva G.V. Methodical recommendations on the use of criterion-diagnostic tools to study the readiness of students to implement the experience of the manifestation of the position of the subject of educational activity. Perspectives of science and education. 2013. no. 6. Available at: https://pnojournal.wordpress.com/2015/06/17/ samuseva-3/ (accessed 17 November 2018) (in Russian)

14. Saralieva Z.Kh. Innovative social macro-, meso-, and microtechnology. Bulletin of the Nizhny Novgorod State 
University named after N.I. Lobachevsky. 2013. no. 3 (3). pp. 229-234. (in Russian)

15. Federal state educational standards of higher professional education (GEF) approved and enforced. [Electronic resource]. Available at: http://www.tusur.ru/ru/ed/education/documents/federal/go. (accessed 17 November 2018) (in Russian)

\section{Информация об авторах \\ Маметьева Ольга Сергеевна (Россия, Магнитогорск)}

Доцент, кандидат педагогических наук, кафедра социальной работы и психологопедагогического образования

Магнитогорский государственный технический университет имени Г. И. Носова E-mail: olga_mametyeva@mail.ru

\section{Бурилкина Светлана Анатольевна} (Россия, Магнитогорск)

Доцент, кандидат социологических наук, кафедра социальной работы и психолого-педагогического образования Магнитогорский государственный технический университет имени Г. И. Носова

E-mail: svetlanaburilkina@yandex.ru

Каминский Александр Сергеевич (Россия, Магнитогорск)

Доцент, кандидат педагогических наук, кафедра социальной работы и

психолого-педагогического образования

Магнитогорский государственный технический университет имени Г. И. Носова

E-mail: a.kaminsky1972@yandex.ru
Information about the authors

Olga S. Mametyeva

(Russia, Magnitogorsk)

Associate Professor,

$\mathrm{PhD}$ in Pedagogical Sciences,

Department of Social Work and Psychological and Pedagogical Education

Nosov Magnitogorsk State Technical University

E-mail: olga_mametyeva@mail.ru

\section{Svetlana A. Burilkina}

(Russia, Magnitogorsk)

Associate Professor,

$\mathrm{PhD}$ in Sociological Sciences,

Department of social work and

psychological and pedagogical education

Nosov Magnitogorsk State Technical University

E-mail: svetlanaburilkina@yandex.ru

\section{Aleksandr S. Kaminskii}

(Russia, Magnitogorsk)

Associate Professor

$\mathrm{PhD}$ in Pedagogical Sciences,

Department of social work and psychological and pedagogical education Nosov Magnitogorsk State Technical University

E-mail: a.kaminsky1972@yandex.ru

\section{For Reference ${ }^{\text {APA }}$}

Mameteva, O. S., Burilkina, S. A., \& Kaminskiy, A. S. (2018). Formation in social sphere specialists their preparedness to implement social technologies in work with families of various types. Perspektivy nauki i obrazovania - Perspectives of Science and Education, 35 (5), 74-84. doi: 10.32744/pse.2018.6.8. (In Russ., abstr. in Engl.) 